\title{
The Literature Review of Innovative Use of Enterprise Information Systems-From the Perspective of Motivation Theory
}

\author{
Yaqin Yu \\ Management School, Jinan University, Guangzhou, China \\ Email: 822575403@qq.com
}

How to cite this paper: Yu, Y.Q. (2016) The Literature Review of Innovative Use of Enterprise Information Systems-From the Perspective of Motivation Theory. Journal of Service Science and Management, 9, 378387.

http://dx.doi.org/10.4236/jssm.2016.95042

Received: September 12, 2016

Accepted: October 7, 2016

Published: October 10, 2016

Copyright $\odot 2016$ by author and Scientific Research Publishing Inc. This work is licensed under the Creative Commons Attribution International License (CC BY 4.0).

http://creativecommons.org/licenses/by/4.0/

\begin{abstract}
The realization of the value of enterprise information systems has been the pressing problem in theoretical and practical circles. Innovative use could tap the potential functions and features of the system and maximize the value and bring considerable business profits for the enterprises. And extrinsic and intrinsic motivations of employees are critical to innovative use. Accordingly, this paper firstly introduces the concept of innovative use, then summarizes the concept and types of extrinsic and intrinsic motivations, next discusses the effect of extrinsic and intrinsic motivations on innovative use. Finally, it points out directions in future research.
\end{abstract}

\section{Keywords}

Innovative Use, Extrinsic Motivation, Intrinsic Motivation, Enterprise Information Systems

\section{(c) (i) Open Access}

\section{Introduction}

With the rapid development of big data, Internet and mobile Internet, the emergence of the new information systems (IS) has brought new development opportunities for the enterprise. IS investments continue to account for a significant proportion of spending in organizations, only 2014, the global business investment in information systems up to $\$ 3.8$ trillion [1]. In fact, the application of enterprise information systems is not so good. Employees just use the system in a standardized way and rarely use the implemented IS to its fullest potential, thus preventing organizations from realizing the promised benefits. The phenomenon of "huge investment, tiny effect" about IS is common, causing scholars' increasing attention to innovative use of IS.

Innovative use, as a form of innovation at the individual level, describes employees' 
application of IS in novel ways to support their work [2], which occurs in the postacceptance stage. Only employees apply the IS in innovative ways, can they realize its further value, contributing to organization gain enormous benefits and sustainable competitive advantage [3]. Innovative use is the exploratory behavior, which relies on employees' higher level of motivation. As the end user of the IS, the extrinsic and intrinsic motivation of employees plays a significant role in innovative use. Therefore, how to stimulate the innovative use effectively? What is the impact mechanism between extrinsic and intrinsic motivation and innovative use? These questions remain the core content in the field of management information system.

Literature review found that scholars hold different standard on specific types of extrinsic and intrinsic motivation because of different perspective. Meanwhile, the extant research conclusions have strong situational dependence. The researchers have not reached a consensus on the relationship between extrinsic and intrinsic motivation and innovative use. Therefore, based on depth study of extant literature, this paper inclines to clarify the evolution of the innovative use in perspective of extrinsic and intrinsic motivation, and serves as a reference for future research.

\section{Innovative Use of IS}

Innovative use, the voluntary behavior of employees in the post-acceptance stage, has been defined from the following two aspects.

On one hand, the system function expansion. Jasperson [2] points out that In the post-acceptance stage, through accumulated experiences with the implemented IS, employees are able to apply the IS in innovative ways, that is, function expansion. This behavior is a kind of incremental innovation, which emphasize on exploring the system, tapping the functions fully, and optimizing the process to support their work better.

On the other hand, Wang and Heish [4] put it that innovative use refers to the user make full use of the system function in order to complete the difficult task, namely system exploration. This behavior emphasizes on system innovation and in the form of novel with unique solutions to support the work, which is a kind of break through innovation.

In conclusion, Innovative use, in which users expand the scope of system features that they use in their work and attempt to find new ways to incorporate the technology in their tasks, involves a continuous cycle of interacting with different features, incorporating them into work routines, and then examining additional features [5] Innovative use happened in infusion phase that is state of post-adoption stage, and recent research emphasizes that the true benefits from IS investments accrue from behaviors that users perform in the post-adoption phase of system introduction [3].

\section{The Concept and Specific Types of Extrinsic and Intrinsic Motivation}

\subsection{The Concept of Extrinsic and Intrinsic Motivation}

Motivation is the internal driving force that influences the individual behavior, mainly 
studies the interaction between human needs, psychological satisfaction, and the relationship between human and environment [6]. Motivation directs and energizes an individual's efforts in conducting relevant tasks and therefore could positively impact the behavioral outcomes [7]. Self-determination theory proposed by Deci and Ryan [6] is developing rapidly and the popular motivation theory, it's hold that motivation is related to individuals' need. According to the causes of motivation, it is mainly manifested in two forms, namely extrinsic motivation and intrinsic motivation. Specifically speaking, extrinsic motivation refers to the impetus to act on acquiring externally administered rewards, including career advancement, prestige, and positive evaluations from others. In contrast, intrinsic motivation is defined as a psychological force arising from personal enjoyment or internalized value of work [7].

There are essential differences between extrinsic and intrinsic motivation, mainly reflected in the following three aspects: First, the purpose. Extrinsic motivation is goaloriented, related to the tangible rewards and environment, while intrinsic motivation is experience-oriented, related to the individual interest, the activity itself [7] [8]. Second, the duration. While extrinsic motivation is often short-lived and could cease once the mandates vanish, intrinsic motivation exists within an individual and is likely to be self-sustainable [9]. Third, the autonomy. Extrinsic motivation make individuals perceived stress and tension, contains low degree of autonomy, while intrinsic motivation let individual feel ease and pleasure, obtains high extent of autonomous [10].

\subsection{The Specific Types of Extrinsic and Intrinsic Motivation}

Prior studies have primarily focused on the role of motivation in user technology acceptance. Davis et al. [11] first related extrinsic motivation (perceived usefulness) toward technology use to efficiency of job related activities. With the deepening of the research, scholars apply motivation theory to explain continuous use, extend use and innovative use of system, having been enriched the forms of extrinsic and intrinsic motivation.

\subsubsection{Extrinsic Motivation}

In the area of information systems, scholars conducted extensive discussion about extrinsic motivation, including perceived usefulness, social influence, affiliation motivation and external regulation, introjected regulation, identified regulation and integrated regulation.

Perceived usefulness (PU) is typically viewed as the most important aspect of extrinsic motivation influencing IS use. As defined by Davis et al. [11], PU refers to users' perceptions of whether using IS will effectively enhance their work performance, comprising of two dimensions that is Perceived efficiency and perceived effectiveness. Perceived efficiency is defined as the extent to which an IS user believes that using the system can increase the output and/or decrease the cost on performing his or her job activities. On the other hand, the perceived effectiveness measures the degree that the users feel the IT/IS can help them get the right things done [12]. Over the past two dec- 
ades, there has been consistent empirical evidence showing that PU is the dominant determinant of IS use. Some concepts are similar to PU, such as "performance expectancy", "relative advantage" and "job fit" [13].

Sun et al. [14] regards social influence which defined as the impact affected by the individuals' environment and groups as extrinsic motivation. Social influence has effect on individuals' behavior mainly through three mechanisms: obedience, internalization and identity. Similarly, Affiliation motivation is a extrinsic motivation, which closely related to social interaction and inspired by the individuals' relationship and interactive demand, it focus on group communication, communication and sense of belonging [8]. In addition, Deci and Ryan [7] classified extrinsic motivation into four types: external regulation, introjected regulation, identified regulation and integrated regulation according to the degree of autonomy. In detail, External regulation means individuals seek for communication with group and a sense of community. With introjected regulation, people have a sense of control because they have to obey some rules and regulations. With identified regulation, people feel greater freedom and volition because the behavior is more congruent with their personal goals and identities. With integrated regulation, people have a full sense that the behavior is an integral part of who they are, that it emanates from their sense of self and is thus self-determined [7].

\subsubsection{Intrinsic Motivation}

Prior IS research on intrinsic motivation has focused on its hedonic dimension [15]. Perceived enjoyment ( $\mathrm{PE}$ ) has typically been viewed as the representative intrinsic motivator for IS use. Admittedly, PE is a salient determinant of individuals' use of technologies. The pleasant sensational experiences of use effectively drive users' interest, ease their cognitive burdens, nurture positive attitudes toward use, and boost use intentions, all of which enhance IS use. Particularly in the case of hedonic IS, the amusement perceived by users can be a critical factor promoting use intentions and behaviors [10].

With the deep research, scholars have been expanding the scope of intrinsic motivation, thus flourishing the extant achievement. Hsu and $\mathrm{Lu}$ [16] pointed out that flow is individuals' subjective sense of fun and absorption, which is related to inner rewards, thus belongs to a deeper intrinsic motivation. Gerow [17] consider that cognitive absorption is a state of cognition state of system participation, which is related to the intrinsic motivation. Drawing on prior studies, Ke et al. [15] conceptualize intrinsic motivation as consisting of two components: intrinsic hedonic and normative motivation. Intrinsic hedonic motivation is propelled by the goal of being engaged in self-determining and competence-enhancing behavior, whereas intrinsic normative motivation is driven by the goal of engaging in behaviors that are compliant with norms and values. In addition, Li et al. [10] also believes that intrinsic motivation is a multidimensional concept that encompasses a sense of accomplishment, satisfaction and stimulation when use system, and thus intrinsic motivation consists of three core aspects: intrinsic motivation toward accomplishment (IMap), intrinsic motivation to know (IMkw), and intrinsic motivation to experience stimulation (IMst). Meanwhile they We define IMap as the pleasure and satisfaction that users experience when solving problems or overcoming 
difficulties in using IS, IMkw as the pleasure and satisfaction that users experience when learning new things or trying to understand something new in using IS, and IMst as the pleasure and satisfaction that users experience when interacting with IS.

\section{Extrinsic and Intrinsic Motivation and Innovative Use}

The relationship between the extrinsic and intrinsic motivation and innovative use has been the focus of scholars. Drawing on the literature review, this paper will illustrate the relationship mechanism between extrinsic and intrinsic motivation and innovative use from two aspects: the direct and indirect effect.

\subsection{The Direct Impact between Extrinsic and Intrinsic Motivation and Innovative Use}

\subsubsection{Extrinsic Motivation and Innovative Use}

There are two different views about the impact of extrinsic motivation on innovative use in academic domain. One view is that the extrinsic motivation can't have a direct impact on innovative use for the reason that innovative use is voluntary behavior which need high autonomy, while extrinsic motivation focus on tangible rewards that could bring some pressure on the staff, thus impeding innovation behavior [18]. Li et al. [10] launched a research concerning the influence mechanism between extrinsic motivation (perceived usefulness) and routine use and innovative use based on the situation in China, they found that perceived usefulness has positive effect on routine use, while no significant impact on innovative use.

Another view is that the extrinsic motivation has do direct impact on innovative use. It is understandable that in workplaces, employees would like to use IS innovative if the enhanced performance derived from IS use can help them accrue job-related benefits, including "raises, promotion, bonuses, and other rewards" [19]. Various empirical researches have confirmed this point. Magni et al. [20] developed a model examining the effects of instrumental (performance expectancy and image enhancement) factors on individuals' intentions to explore at echnology from the dynamic perspective, After nearly a year of longitude study, they found that performance expectations and image enhancement affect individuals' intentions to explore positively, and as time goes by, the extent will gradually increase. Ke and Zhang [21] examined the effects of external regulation, introjected regulation, identified regulation and integrated regulation on employees' participation in OSS software development. The result demonstrated that external regulation, introjected regulation, identified regulation and integrated regulation is the key factors that affect employees' involvement in software development, particularly, when the development process fully meet the employees' autonomy, competence and relatedness demand, the impact will be more significant. In addition, Koo and Chung [22] also get the same conclusion, that is, these four extrinsic motivations have impact on new energy-efficient systems.

\subsubsection{Intrinsic Motivation and Innovative Use}

According to creativity theory [23], complex, innovative, and extra-role tasks such as 
ES feature exploration require users to be intrinsically motivated [15]. Therefore, researches have come into agreement that intrinsic motivation is the vital agency which affects innovative use. Magni et al. [20] contend that cognitive absorption can encourage employees to explore the system through inspiring their identification and engagement of system. Ke et al. [15] examined the relationship between intrinsic motivation (intrinsic hedonic and normative motivation) and system exploration behavior, the result demonstrated that intrinsic hedonic motivation energizes users to focus on the sensation of exploring innovative ways of applying IS features, normative motivation gives users the desire to act appropriately and leads users to consciously exercise discretion in their explorations, thus both have positive effects on exploratory usage, even though the linkage between intrinsic normative motivation and exploratory usage is insignificant. Although generally recognized by the academia that intrinsic motivation has a direct effect on innovative use, but Li et al. [10] consider that not all types of intrinsic motivation have a significant effect on innovative use. Based on Chinese situation they embark on a research that explore the effect of intrinsic motivation toward accomplishment, intrinsic motivation to know, and intrinsic motivation to experience stimulation to innovative use, the empirical results show that only intrinsic motivation to know, and intrinsic motivation to experience stimulation has a significant positive relationship with innovative use, otherwise the intrinsic motivation toward accomplishment.

\subsection{The Indirect Impact between Extrinsic and Intrinsic Motivation and Innovative Use}

In order to understand the influence mechanism, then open the black box between extrinsic and intrinsic motivation and innovative use. In recent years, researches conduct various deep studies to classify these issues Figure 1. Ke and Wei [9] pointed out that intrinsic motivation is consistently found to be critical for users' exploratory usage of IS features, which is in accord with what is suggested by the Creativity Theory, which posits that complex, innovative and extra-role tasks such as IS feature exploration requires the individual to be intrinsically motivated, so previous studies have focused on the ef-

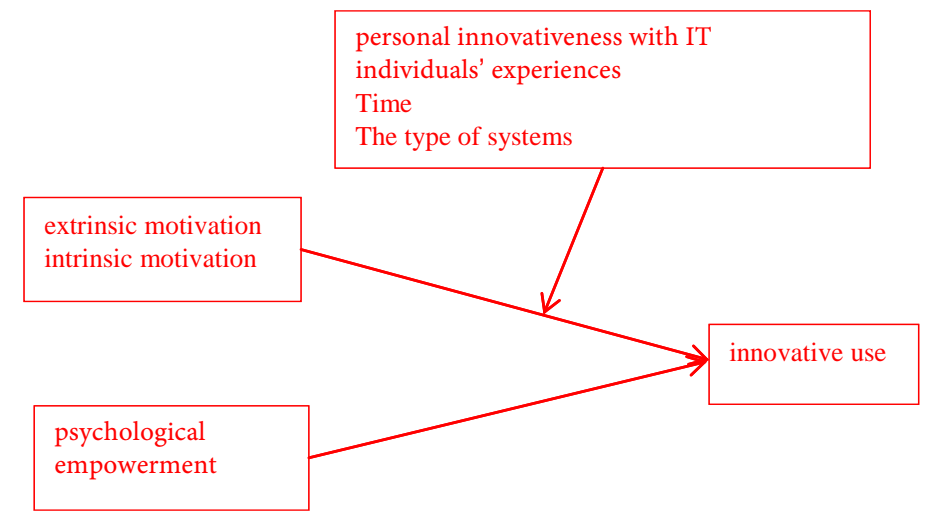

Figure 1. Indirect impact between extrinsic and intrinsic motivation and innovative use. 
fects of intrinsic motivation on innovative use simply and ignored that of the exploration process. Yet, the Componential Theory of Creativity suggests that motivation is necessary, but not sufficient, for creative outcomes. People's engagement in innovative process matters and their experience with the process will affect the outcomes of their goal pursuit [18]. Therefore, they investigate the joint effect of psychological empowerment, which is identified as such an important factor that has the potential to affect individuals' involvement in creative work process and intrinsic motivation on IS exploratory usage. The result posits that intrinsic motivation (hedonic and normative motivations) and psychological empowerment have positive effects on users' exploration usage of the system. Furthermore, psychological empowerment magnifies the value of the object pursued, and thus strength the effects of intrinsic motivation on exploratory usage.

Meanwhile, some scholars introduce the moderator variable to optimize the analysis framework. Li et al. [10] point out that personal innovativeness with IT, which refers to the degree to which an individual is willing to try out a new technology and characterizes individuals' risk taking propensity and tolerance of uncertainty during the technology use process, positively moderates the impact of intrinsic motivation on innovative use. Magni et al. [20] have conducted the dynamic research, that is, investigated the effect of hedonic and instrumental factors on innovation use over time. The results show that the effect of hedonic factors decreases and instrumental agency increases as time goes by and individuals' experiences increase because the interaction between employees and system would increase, which contribute system use to routine and automation.

In addition, the system itself is the indispensable moderator can't be ignored. $\mathrm{Wu}$ and $\mathrm{Lu}[8]$ pointed out that extrinsic and intrinsic motivation have different impact on system use behavior with different system (utilitarian systems, hedonic system and dual-purposed system): in the context of utilitarian systems, extrinsic motivators are more important than intrinsic motivators, whereas, in the context of hedonic systems, intrinsic motivators play a more critical role than extrinsic motivators. Likewise, Hsu and $\mathrm{Lu}$ [16] also confirmed that perceived usefulness only has effect on utilitarian systems use behavior, while no effect on hedonic one. However, Gerow et al. [17] hold different conclusions. They found that the intrinsic motivation and utilitarian system, extrinsic motivation and hedonic system also has certain contact to some extent.

From the above literature review, we conclude that the direct effect mainly focus on weather extrinsic and intrinsic motivation can contribute to innovation use behavior, while indirect effect emphasize investigate the joint effect of extrinsic and intrinsic motivation and other relative factors on innovation use or explore their moderate effect. Drawing on extant research, we find that scholars don't come into converage concerning weather extrinsic motivation has direct effect on innovative use. In addition, although scholars generally believe that the intrinsic motivation has a positive impact on innovative use, but not all intrinsic motivation types have a significant effect on its. And these issues need further theoretical discussion and empirical test. 


\section{The Future Research Prospects}

Based on the review of the extant literature, this paper reviews the research from the perspective of extrinsic and intrinsic motivation, and puts forward the prospect of the future research from following three aspects: the research theme, research methods and research situation: First, the theme of research. To further clarify the effect of extrinsic and intrinsic motivation on innovative use, existing studies have demonstrated that extrinsic and intrinsic motivation has positive effect on innovative use, but do not explore how the effect works. And scholars have not come into consensus on whether extrinsic motivation has direct effect on innovative use. So, the future research should be aimed at addressing those issues. Second, the method of research. On one hand, enriching the research methods. At present, most of the research on this theme is empirical research, and questionnaire and field study are the majority. But both approaches are still some defects: collecting data mainly through subjective questionnaires. It can't avoid measurement errors, while field research may appear "Hawthorne effect", leading to results inaccurate. In view of this, the future research should be combined with other research methods, such as case studies, to make up for the shortcomings of existing research. On the other hand, strengthening the dynamic research. Most studies are based on static assumption, which ignores the process of dynamic change. In fact, researches on the impact and development process involve the time dimension, in order to better clarify the extrinsic and intrinsic influence over the innovative use. Future research should adopt dynamic research, that is, the variable is measured at different points. For example, with the system adopted, what are the morphological changes on innovative use over time? Is the effect of extrinsic and intrinsic motivation on the innovative use enhanced or diminished as time goes by? These issues are worth-while to further exploration. Third, the situation of research. Most of the extant researches are based on western situation, relatively scarce in the context of China. Thus, the future studies should be designed to develop the scale of innovative use which is suitable for the Chinese context, to strengthen the localization of China's empirical research, and take the change of industrial structure of China into consideration when selecting the appropriate sample in order to better study the innovation use in Chinese situation. For example, the emergence of new information systems based on big data and mobile Internet. It provides a broader research platform for innovative use. Therefore, the future research should closely follow the pace of times and environment, to provide practical guidance and inspiration for Chinese enterprises.

\section{References}

[1] Gartner (2014) Gartner Says Worldwide IT Spending on Pace to Reach \$3.8 Trillion in 2014. http://www.gartner.com/newsroom/id/2643919

[2] Jasperson, J. and Zmud, R.W. (2005) A Comprehensive Conceptualization of Post-Adoptive Behaviors Associated with Information Technology Enabled Work Systems. MIS Quarterly, 29, 525-557.

[3] Hsieh, P.A., Rai, A. and Xu, S.X. (2011) Extracting Business Value from IT: A Sense-Mak- 
ing Perspective of Post-Adoptive Use. Management Science, 57, 2018-2039.

http://dx.doi.org/10.1287/mnsc.1110.1398

[4] Beyond Routine (2006) Symbolic Adoption, Extended Use, and Emergent Use of Complex Information Systems in the Mandatory Organizational Context. ICIS 2006 Proceedings. Paper 48. http://aisel.aisnet.org/icis2006/48

[5] Maruping, L.M. and Magni, M. (2015) Motivating Employees to Explore Collaboration Technology in Team Contexts. MIS Quarterly, 39, 1-16.

[6] Deci, E.L., Nezlek, J. and Sheinman, L. (1980) Characteristics of the Rewarder and Intrinsic Motivation of the Rewardee. Journal of Personality \& Social Psychology, 40, 1-10. http://dx.doi.org/10.1037/0022-3514.40.1.1

[7] Deci, E.L. and Ryan, R.M. (2000) The "What" and "Why" of Goal Pursuits: Human Needs and The Self-Determination of Behavior. Psychological Inquiry, 11, 227-268.

http://dx.doi.org/10.1207/S15327965PLI1104 01

[8] Wu, J. and Lu, X. (2013) Effects of Extrinsic and Intrinsic Motivators on Using Utilitarian, Hedonic, and Dual-Purposed Information Systems: A Meta-Analysis. Journal of the Association for Information Systems, 14, 153-191.

[9] Ke, W.L. and Wei, K.K. (2015) Exploratory Usage of Enterprise Systems: The Joint Effects of Intrinsic Motivation and Psychological Empowerment. PACIS 2015 Proceedings. Paper 232. http://aisel.aisnet.org/pacis2015/232

[10] Li, X., Hsieh, P.A. and Rai, A. (2013) Motivational Differences across Post-Acceptance Information System Usage Behaviors: An Investigation in the Business Intelligence Systems Context. Information Systems Research, 24, 659-682.

http://dx.doi.org/10.1287/isre.1120.0456

[11] Davis, F.D., Bagozzi, R.P. and Warshaw, P.R. (2006) Extrinsic and Intrinsic Motivation to Use Computers in the Workplace 1. Journal of Applied Social Psychology, 22, 1111-1132. http://dx.doi.org/10.1111/j.1559-1816.1992.tb00945.x

[12] Yeh, R.K.-J. and Teng, J.T.C. (2012) Extended Conceptualisation of Perceived Usefulness: Empirical Test in the Context of Information System Use Continuance. Behaviour \& Information Technology, 31, 525-540. http://dx.doi.org/10.1080/0144929X.2010.517272

[13] Venkatesh, V., Morris, M.G., Davis, G.B. and Davis, F.D. (2003) User Acceptance of Information Technology: Toward a Unified View. MIS Quarterly, 27, 425-478.

[14] Sun, J.Y., Han, S.H. and Huang, W. (2012) The Roles of Intrinsic Motivators and Extrinsic Motivators in Promoting E-Learning in the Workplace: A Case from South Korea. Computers in Human Behavior, 28, 942-950. http://dx.doi.org/10.1016/j.chb.2011.12.015

[15] Ke, W.L., Tan, C.H., Sia, C.L. and Wei, K.K. (2012) Inducing Intrinsic Motivation to Explore the Enterprise System: The Supremacy of Organizational Levers. Journal of Management Information Systems, 29, 257-289. http://dx.doi.org/10.2753/MIS0742-1222290308

[16] Hsu, C.L. and Lu, H.P. (2004) Why Do People Play On-Line Games? An Extended TAM with Social Influences and Flow Experience. Information \& Management, 41, 853-868. http://dx.doi.org/10.1016/j.im.2003.08.014

[17] Gerow, J.E., Ayyagari, R., Thatcher, J.B., et al. (2013) Can We Have Fun @ Work? The Role of Intrinsic Motivation for Utilitarian Systems. European Journal of Information Systems, 22, 360-380. http://dx.doi.org/10.1057/ejis.2012.25

[18] Amabile, T.M. (2010) Motivation and Creativity: Effects of Motivational Orientation on Creative Writers. Journal of Personality \& Social Psychology, 48, 393-399.

[19] Karahanna, E. and Agarwal, R. (2011) When the Spirit Is Willing: Symbolic Adoption and 
Technology Exploration, 2011. Unpublished Manuscript, University of Georgia, Athens.

[20] Magni, M., Taylor, M.S. and Venkatesh, V. (2010) To Play or Not to Play: A Cross-Temporal Investigation Using Hedonic and Instrumental Perspectives to Explain User Intentions to Explore a Technology. International Journal of Human-Computer Studies, 28, 572588. http://dx.doi.org/10.1016/j.ijhcs.2010.03.004

[21] Ke, W.L. and Zhang, P. (2010) The Effects of Extrinsic Motivations and Satisfaction in Open Source Software Development. Journal of the Association for Information System, 11, 784-808.

[22] Koo, C. and Chung, N. (2014) Examining the Eco-Technological Knowledge of Smart Green IT Adoption Behavior: A Self-Determination Perspective. Technological Forecasting \& Social Change, 88, 140-155. http://dx.doi.org/10.1016/j.techfore.2014.06.025

[23] Amabile, T.M. (1996) Creativity in Context: Update to the Social Psychology of Creativity. High Ability Studies, 2, 100-101.

Submit or recommend next manuscript to SCIRP and we will provide best service for you:

Accepting pre-submission inquiries through Email, Facebook, LinkedIn, Twitter, etc. A wide selection of journals (inclusive of 9 subjects, more than 200 journals)

Providing 24-hour high-quality service

User-friendly online submission system

Fair and swift peer-review system

Efficient typesetting and proofreading procedure

Display of the result of downloads and visits, as well as the number of cited articles

Maximum dissemination of your research work

Submit your manuscript at: http://papersubmission.scirp.org/

Or contact jssm@scirp.org 